CHRONIC OBSTRUCTIVE PULMONARY DISEASE

\title{
Developing COPD: a 25 year follow up study of the general population
}

\author{
A Løkke, P Lange, H Scharling, P Fabricius, J Vestbo
}

Thorax 2006;61:935-939. doi: 10.1136/thx.2006.062802

See end of article for authors' affiliations .....................

Correspondence to: Dr P Lange, Department of Cardiology and Respiratory Medicine, 253 Hvidovre Hospital, Kettegård Alle 30, DK2650 Hvidovre, Denmark; peter.lange@hh.hosp.dk

Received 21 March 2006 Accepted 22 May 2006
Background: Smokers are more prone to develop chronic obstructive pulmonary disease (COPD) than non-smokers, but this finding comes from studies spanning 10 years or less. The aim of this study was to determine the 25 year absolute risk of developing COPD in men and women from the general population. Methods: As part of the Copenhagen City Heart Study, 8045 men and women aged 30-60 years with normal lung function at baseline were followed for 25 years. Lung function measurements were collected and mortality from COPD during the 25 year observation period was analysed.

Results: The percentage of men with normal lung function ranged from $96 \%$ of never smokers to $59 \%$ of continuous smokers; for women the proportions were $91 \%$ and $69 \%$, respectively. The 25 year incidence of moderate and severe COPD was $20.7 \%$ and $3.6 \%$, respectively, with no apparent difference between men and women. Smoking cessation, especially early in the follow up period, decreased the risk of developing COPD substantially compared with continuous smoking. During the follow up period there were 2912 deaths, 109 of which were from COPD. 92\% of the COPD deaths occurred in subjects who were current smokers at the beginning of the follow up period.

Conclusion: The absolute risk of developing COPD among continuous smokers is at least $25 \%$, which is larger than was previously estimated.
C hronic obstructive pulmonary disease (COPD) is one of the leading causes of morbidity and mortality worldwide and is expected to increase in coming decades. ${ }^{1-3}$ Tobacco smoking is the most important risk factor for developing COPD. The deleterious effect of smoking is mainly mediated through an accelerated decline in forced expiratory volume in 1 second $\left(\mathrm{FEV}_{1}\right)$ in adulthood, which over the years results in a substantial reduction in lung function leading to symptomatic disease. Many longitudinal studies have provided data on the increased relative risk of developing COPD in smokers compared with non-smokers, ${ }^{4-8}$ and both observational studies and a single major intervention study have described a reduction in the excessive decline in $\mathrm{FEV}_{1}$ following smoking cessation. ${ }^{8-10}$ The development of COPD usually takes several decades, but most of the longitudinal studies of COPD only span 5-10 years. Therefore, even today, more than 25 years after the publication of the seminal study of Fletcher et al describing the natural history of COPD, ${ }^{4}$ our knowledge on the rate of development and progression of COPD in individual smokers stems from extrapolating results from individuals followed for relatively short periods. Moreover, most of our knowledge is based on observations in selected occupational or patient cohorts, all with a predominance of men.

The aim of the present study was to determine the absolute risk of developing COPD in men and women from the general population and to relate this risk to changes in tobacco consumption during a long observation period, allowing for estimates of absolute risk that approach the "life risk". The data used were taken from the four examinations of the Copenhagen City Heart Study, a longitudinal study of several thousand individuals selected from the general population of the city of Copenhagen and followed for 25 years.

\section{METHODS}

All individuals included in this study participated in the Copenhagen City Heart Study, an ongoing epidemiological study of the inhabitants of the inner city of Copenhagen,
Denmark. ${ }^{11}{ }^{12}$ In 1976 a sample of 19698 persons aged 20 years or older, selected at random and stratified into 10 year age groups, were invited to participate in the study. A total of 14223 attended the first examination in 1976-8 (response rate $74 \%$ ). A cohort of 8045 individuals aged 3060 years with sufficient smoking and spirometric data was selected from the study participants for the present analyses. The 30 years of age criterion was chosen to ensure that maximally attained lung function had been reached. Only subjects with normal lung function were included. Patients with asthma at baseline were excluded. We followed the convention of other epidemiological studies by relying on the subjects' perception of whether or not they have the disease. ${ }^{13}$ Thus, asthma was defined by an affirmative response to the question: "Do you have asthma?" and 171 subjects gave an affirmative answer. The local ethics committee approved the study protocol and informed consent was obtained from all participants.

Data on mortality from COPD for the 8045 participants were obtained from the Danish Death Register. The development of COPD among the study participants was assessed from subsequent spirometric examinations: the second in 1981-3, the third in 1991-4, and the fourth in 2001-3. Analyses of spirometric findings were performed in the following two subgroups:

- 2442 individuals who participated in the first and fourth examinations (but not necessarily in the second and third examinations).

- 2022 individuals who participated in all four subsequent examinations throughout the 25 year follow up, which allowed us to relate changes in smoking habits during the observation period to the risk of developing COPD from 1976 to 2004.

Abbreviations: $\mathrm{COPD}$, chronic obstructive pulmonary disease; $\mathrm{FEV}_{1}$, forced expiratory volume in 1 second; FVC, forced vital capacity 
Table 1 All-cause and COPD deaths over time in the entire cohort

\begin{tabular}{lcccccr}
\hline & $\mathbf{0 - 5}$ years & $\mathbf{5 - 1 0}$ years & $\mathbf{1 0 - 1 5}$ years & $\mathbf{1 5 - 2 0}$ years & 20-25 years & Entire period \\
\hline All deaths & 235 & 413 & 563 & 841 & 860 & 2912 \\
COPD deaths & 1 & 2 & 15 & 36 & 55 & 109 \\
\hline
\end{tabular}

At the fourth examination all subjects reported whether they were current smokers, ex-smokers, or never smokers. Using this information, we defined the following subgroups: never smokers; ex-smokers (those who had stopped smoking before enrolment); early smoking cessation (those who stopped smoking between the first and second surveys); intermediate smoking cessation (those who stopped smoking between the second and third surveys); late smoking cessation (those who stopped smoking between the third and fourth surveys); and continuous smokers (those who continued smoking throughout the entire follow up period). Subjects were also asked about education and whether or not they had ever been exposed to dust and welding fumes in the workplace.

At the first and second examinations, $\mathrm{FEV}_{1}$ and forced vital capacity (FVC) were measured with an electronic spirometer (N 403 Monaghan, Littleton, USA) which was calibrated daily with a 1 litre syringe and weekly against a water sealed Goddard spirometer. The Monaghan spirometer stopped functioning between the second and third examinations, and at the third and fourth examinations a dry wedge spirometer (Vitalograph, Maidenhead, UK) calibrated daily with a 1 litre syringe was used. At each examination three sets of values were obtained and, as a criterion for correct performance of the procedure, at least two measurements differing by less than $5 \%$ had to be produced. The highest measurements of $\mathrm{FEV}_{1}$ and FVC were used in the analyses as absolute values and as percentage of predicted values using internally derived reference values based on a subsample of healthy never smokers: ${ }^{14}$

Women: $\mathrm{FEV}_{1}(\mathrm{ml})=410-27.6 \times$ age $($ years $)+21.2 \times$ height $(\mathrm{cm})$

Men: $\mathrm{FEV}_{1}(\mathrm{ml})=-469-35.2 \times$ age $($ years $)+32.0 \times$ height $(\mathrm{cm})$

The predicted values obtained from these equations were concordant with reference values for normal subjects published by the Danish Lung Association. ${ }^{15}$ Staging was done according to the criteria of the American Thoracic Society and the European Respiratory Society: ${ }^{2}$

- Stage 1: $\mathrm{FEV}_{\mathrm{l}} / \mathrm{FVC}<70 \%$ and $\mathrm{FEV}_{1}>80 \%$ predicted

- Stage 2: $\mathrm{FEV}_{1} / \mathrm{FVC}<70 \%$ and $50 \%>\mathrm{FEV}_{1}<80 \%$ predicted

- Stage 3: $\mathrm{FEV}_{1} / \mathrm{FVC}<70 \%$ and $30 \%>\mathrm{FEV}_{1}<50 \%$ predicted

- Stage 4: $\mathrm{FEV}_{1} / \mathrm{FVC}<70 \%$ and $\mathrm{FEV}_{1}<30 \%$ predicted
The term "no COPD" was used for all those with normal spirometric parameters regardless of exposure to risk factors or presence of chronic symptoms.

For the mortality analyses, data from the Danish Death Register were used. Since Denmark used both the 8th and 10th International Classification of Diseases (ICD) during the observation period, deaths from COPD were those where the main diagnosis on the death certificate was either ICD8: 491492 or ICD10: J41-44.

\section{Statistical methods}

Incidence rates were calculated from the 25 year incidence observed and expressed as percentage per 25 years. As fixed periods of follow up were used with little variance in time between examinations, a multivariate logistic regression model was used. The following variables were considered as potential confounders for changes in COPD stage: age, sex, smoking (yes/no), time of smoking cessation (early, intermediate, late), education (low, middle, or high), and exposure to welding dust (yes/no). SPSS Version 12.0, SAS, and STATA were used for calculating all statistics.

\section{RESULTS}

The 8045 subjects included in the mortality analysis consisted of 5280 smokers, 1513 never smokers, and 1252 ex-smokers. During the 25 year follow up period 2912 deaths occurred, including 109 deaths from COPD. Table 1 shows the distribution of deaths during the observation period. Deaths from COPD constituted $3.7 \%$ of all deaths and, as expected, there were almost no COPD deaths during the first 10 years of follow up. Only two COPD deaths occurred in nonsmokers, 100 deaths occurred in those who were active smokers at the beginning of the observation period, and seven COPD deaths occurred in ex-smokers.

Among the 2022 participants with 25 years of spirometric data, 581 were never smokers, 371 were ex-smokers, 93 were smokers with early smoking cessation, 153 were smokers with intermediate smoking cessation, 210 were smokers with late smoking cessation, and 614 were continuous smokers. Table 2 shows the baseline characteristics for these six subgroups. There were more female never smokers but otherwise there were no obvious differences between the smoking habits of men and women. The characteristics of the 2442 participants who had only the first and fourth

Table 2 Baseline characteristics for 2022 subjects who participated in all four examinations

\begin{tabular}{|c|c|c|c|c|c|c|c|}
\hline & $\begin{array}{l}\text { Never smokers } \\
(n=581)\end{array}$ & $\begin{array}{l}\text { Ex-smokers } \\
(n=371)\end{array}$ & $\begin{array}{l}\text { Early cessation } \\
(\mathrm{n}=93)\end{array}$ & $\begin{array}{l}\text { Intermediate } \\
\text { cessation } \\
(n=153)\end{array}$ & $\begin{array}{l}\text { Late cessation } \\
(n=210)\end{array}$ & $\begin{array}{l}\text { Continuous } \\
\text { smokers } \\
(n=614)\end{array}$ & $\begin{array}{l}\text { All } \\
(n=2022)\end{array}$ \\
\hline Age (years) & 45.7 & 47.3 & 45.1 & 46.9 & 44.4 & 44.2 & 45.4 \\
\hline Women (\%) & 75.7 & 56.3 & 54.8 & 47.1 & 55.2 & 58.3 & 61.6 \\
\hline $\begin{array}{l}\text { Age when started } \\
\text { smoking (years) }\end{array}$ & - & 18.4 & 20.6 & 19.2 & 19.8 & 19.0 & 19.2 \\
\hline Pack-years (years) & - & - & 14.8 & 18.4 & 16.7 & 19.1 & 18.2 \\
\hline $\begin{array}{l}\text { Exposure to welding } \\
\text { dust (\%) }\end{array}$ & 8.6 & 10.0 & 5.3 & 17.0 & 12.9 & 16.1 & 12.1 \\
\hline No education (\%) & 25.7 & 26.6 & 24.2 & 22.9 & 29.5 & 27.2 & 26.5 \\
\hline High education (\%) & 6.9 & 8.4 & 7.7 & 7.2 & 5.2 & 5.4 & 6.6 \\
\hline
\end{tabular}


Table 3 Incidence of COPD stage 1, 2, and 3-4 among women participating in all four examinations from 1976 to 2004

\begin{tabular}{llllll}
\hline & N at baseline & No COPD & COPD stage 1 & COPD stage 2 & COPD stage 3-4 \\
\hline Never smokers & 440 & $401(91)$ & $13(3)$ & $22(5)$ & $4(1)$ \\
Ex-smokers & 209 & $186(89)$ & $10(5)$ & $10(5)$ & $3(1)$ \\
Early cessation & 51 & $41(80)$ & $4(8)$ & $6(12)$ & $0(0)$ \\
Intermediary cessation & 72 & $54(75)$ & $6(8)$ & $9(13)$ & $3(4)$ \\
Late cessation & 116 & $83(71)$ & $9(8)$ & $17(15)$ & $7(6)$ \\
Continuous smokers & 358 & $246(69)$ & $33(9)$ & $71(20)$ & $8(2)$ \\
\hline
\end{tabular}

Data are shown as $n(\%)$.

examinations did not differ significantly from the 2022 who participated in all four examinations.

Tables 3 and 4 show the distribution of men and women, respectively, with different stages of COPD after 25 years of follow up. The effects of smoking and of a delay in smoking cessation are clearly seen. For both men and women there is a remarkable decline in the percentage of healthy subjects from over $90 \%$ among never-smokers to approximately $65 \%$ for continuous smokers. The reverse is seen for all of the COPD stages with a progressive increase in the percentage of subjects with impaired lung function from $3 \%$ in stage 1 for never smokers to a maximum of $14 \%$ for male continuous smokers, from $1 \%$ in stage 2 for never smokers to $22 \%$ for continuous smokers, and from none in stage 3-4 for never smokers to $5 \%$ for continuous smokers. Table 5 shows that the distribution of the two sexes among the 2442 subjects who participated in the first and fourth examinations only was similar.

Figure 1 shows the calculated incidence rates for COPD stage 1, 2, and 3-4 for men and women. The highest incidence was seen in continuous smokers, which for all stages of COPD was $35.5 \%$ over the 25 year period. The similar incidence for never smokers was $7.8 \%$. Among continuous smokers, $24.3 \%$ developed clinically significant COPD (stage 2 or worse). It is also noteworthy that, with the present staging system, more patients have stage 2 disease than stage 1 or $3-4$.

Figure 2 shows statistically significant predictors of COPD stage 2 or worse expressed as odds ratios (ORs). Age was a significant predictor whereas sex was not. As in the incidence tables, smoking characteristics were significant predictors of clinical COPD. The OR for developing clinically significant COPD was 6.3 (95\% confidence interval (CI) 4.2 to 9.5) for a continuous smoker compared with a never smoker, with decreasing ORs with increasing duration of smoking abstinence. Occupational exposures and educational level did not have any major impact on the risk of developing COPD.

\section{DISCUSSION}

This study has examined the risk of developing of COPD in a general population throughout an observation period of 25 years. Our estimates indicate that, after 25 years of smoking, at least $25 \%$ of smokers without initial disease will have clinically significant COPD and $30-40 \%$ will have any COPD. As our spirometric study only includes survivors and responders throughout the 25 year period, the true risk must be even higher, which is underlined by the fact that 109 ( $1.4 \%)$ died from COPD. Our main finding is quite simple: the longer people smoke, the higher the risk of developing COPD. Most importantly, quitting smoking does make a substantial difference; in fact, none of the early quitters with complete follow up developed severe COPD even after 25 years and the number of deaths from COPD among those who were exsmokers was much lower $(0.6 \%)$ than the number observed in smokers $(2 \%)$. Thus, whereas the risk of developing COPD in ex-smokers and never smokers differed only slightly, the risk in those who stopped smoking late and continuous smokers was very similar. The most likely explanation for this is that late quitters often stop as a result of their COPD and, since smoking cessation has only a minor effect on $\mathrm{FEV}_{1}$, once COPD has developed, the effect of quitting has little if any impact on the long term incidence of COPD.

Only a few studies of the incidence of COPD have been published and all have spanned a shorter time period than our study. ${ }^{16-19}$ Our findings are in accordance with those of a recent large Swedish study showing a 10 year cumulative incidence of $13.5 \% .{ }^{19}$ Whatever the true size of the cumulative incidence, it seems clear that the usual statement that "10$15 \%$ of smokers develop COPD" is wrong and has probably had a significant and negative impact on our understanding of COPD. ${ }^{20}$ One of the most important factors determining the prevalence of COPD is the age distribution of the population. In most western countries, life expectancy is still increasing. This explains why the prevalence of COPD will remain high in the western world for many years to come in spite of a substantial reduction in smoking habits. In addition, the fact that death from ischaemic heart disease has declined increases the likelihood that smokers will live long enough to develop COPD.

The effect of smoking cessation on the risk of developing COPD was profound and our findings support previous studies in more selected populations. In the Lung Health Study the progression of COPD in continuous smokers was halted by smoking cessation $^{10}$ leading to a significant decrease in patients with moderate and severe COPD at 11 year follow up. ${ }^{21}$ Moreover, the beneficial effect of smoking cessation is not limited to COPD, not even in patients with COPD. ${ }^{22}$

The findings from our study may not have global significance. The major exposure causing COPD in

Table 4 Incidence of COPD stage 1, 2, and 3-4 among men participating in all four examinations from 1976 to 2004

\begin{tabular}{|c|c|c|c|c|c|}
\hline & $\mathrm{N}$ at baseline & No COPD & COPD stage 1 & COPD stage 2 & COPD stage $3-4$ \\
\hline Never smokers & 141 & $135(96)$ & $5(3)$ & $1(1)$ & $0(0)$ \\
\hline Ex-smokers & 162 & $143(88)$ & $7(5)$ & $10(7)$ & $2(1)$ \\
\hline Early cessation & 42 & $40(95)$ & $1(2.5)$ & $1(2.5)$ & $0(0)$ \\
\hline Intermediary cessation & 81 & $70(86)$ & $0(0)$ & $9(11)$ & $2(3)$ \\
\hline Late cessation & 94 & 71 (76) & $9(9.5)$ & $9(9.5)$ & $5(5)$ \\
\hline Continuous smokers & 256 & $150(59)$ & $36(14)$ & $56(22)$ & $14(5)$ \\
\hline
\end{tabular}

Data are shown as $n(\%)$. 
Table 5 Incidence of COPD stage 1, 2, and 3-4 among men and women participating in the first and fourth examinations only

\begin{tabular}{|c|c|c|c|c|c|}
\hline & $\mathrm{N}$ at baseline & No COPD & COPD stage 1 & COPD stage 2 & COPD stage $3-4$ \\
\hline \multicolumn{6}{|l|}{ Women } \\
\hline Never smokers & 493 & $449(91)$ & $15(3)$ & $24(5)$ & $5(1)$ \\
\hline Ex-smokers & 259 & $228(88)$ & $13(5)$ & $14(5)$ & $4(2)$ \\
\hline Quitters & 286 & $217(76)$ & $22(8)$ & $36(13)$ & $11(4)$ \\
\hline Continuous smokers & 422 & $294(70)$ & $38(9)$ & 80 (19) & $10(2)$ \\
\hline \multicolumn{6}{|l|}{ Men } \\
\hline Never smokers & 174 & $165(95)$ & $8(5)$ & $1(1)$ & $0(0)$ \\
\hline Ex-smokers & 207 & $181(87)$ & $9(4)$ & $14(7)$ & $3(1)$ \\
\hline Quitters & 263 & $215(82)$ & $12(5)$ & 29 (11) & 7 (3) \\
\hline Continuous smokers & 338 & $206(61)$ & 47 (14) & $67(20)$ & $18(5)$ \\
\hline
\end{tabular}

Data are shown as $\mathrm{n}(\%)$.

Copenhagen is smoking and, although occupational exposures may be of some importance for COPD in industrialised countries, ${ }^{123}$ exposure to welding dust had no influence in our setting. Also, in less industrialised countries, burning of biomass fuel is a major exposure responsible for COPD; our study was unable to evaluate the time course of subjects with this particular exposure. However, half of the approximately 5 million deaths caused by smoking in 2000 occurred in developing countries, and the proportion is certain to rise in the years to come. ${ }^{24}$

Our study has other potential shortcomings. We have not taken into account the total number of years or the total amount of tobacco any given individual has smoked by the end of the follow up period as the data necessary for doing so were not available. Most importantly, however, our findings almost certainly underestimate the "truth about the lifelong risk of developing COPD" because of selection bias. All participants were invited to attend four times over a 25 year period, something that the elderly and those with the most impaired lung function are less likely to do than the young and healthy. Of the initial cohort of 8045 participants at the first examination we observed 2912 deaths during the follow up period, which leaves 5133 potential participants for the fourth examination. Since only 2442 participated, our follow up rate for spirometric testing after 25 years is approximately $48 \%$ in contrast to the $100 \%$ follow up rate for mortality. A previous examination has shown that non-responders were less healthy than responders, so our estimates are undoubtedly lower than if the spirometric follow up had been complete..$^{25}$ In addition, we observed a substantial number of deaths from COPD in the latest period of the 25 year follow up period (table 1) even though all the participants had normal lung function at the beginning of the study period. If deaths recorded as being due to COPD are counted as incident cases of COPD, the incidence of COPD in smokers is at least $25 \%$ higher than that shown in tables 3 and 4 and in fig 1. In addition, even mild COPD—which is often

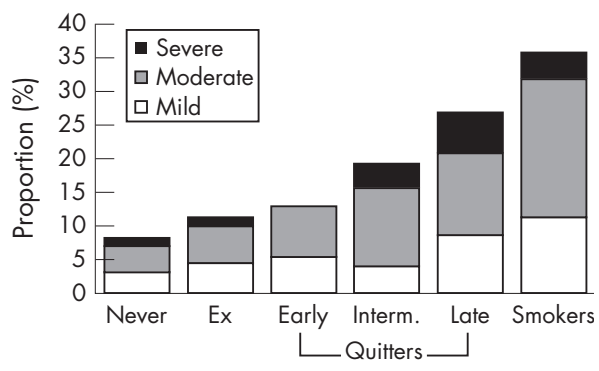

Figure 1 Calculated cumulative incidence for COPD according to GOLD stages, men and women combined.

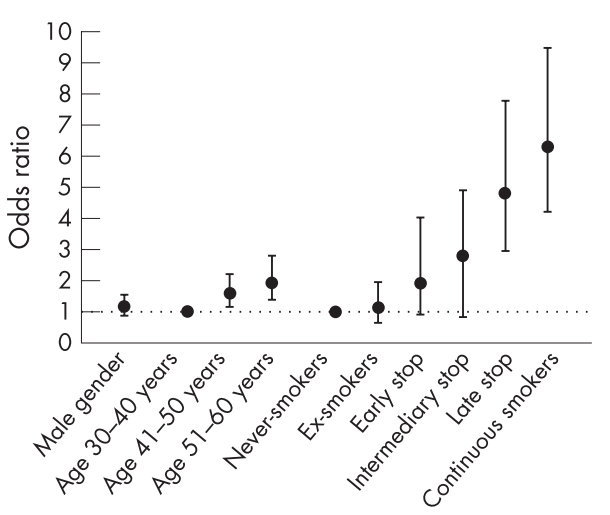

Figure 2 Statistically significant predictors of COPD stage 2 or worse expressed as odds ratios and $95 \%$ confidence intervals.

considered as a disease of little clinical significance-has been found to increase mortality by approximately $25 \%$ in the general population. ${ }^{26}$

Despite these shortcomings, the results are clear. The percentage of healthy participants falls dramatically from more than $90 \%$ for never smokers to around $60-70 \%$ for continuous smokers, regardless of sex. In fact, contrary to some of our previous reports, no clear differences in the development of COPD were found between men and women. The most likely explanation for this is the way that smoking was handled in the regression analysis; the higher risk in women appears only if one includes a very detailed measure of tobacco consumption, whereas in the present analyses we used a much cruder classification of smokers versus nonsmokers. This means that, although women may have a slightly higher risk of COPD per gram of tobacco smoked, the fact that men still smoke more tobacco daily than women will mask this difference. With the current smoking pattern in industrialised countries, COPD is becoming as frequent in women as in men. ${ }^{27}$

Most previous studies have provided relative risks of COPD in smokers compared with non-smokers, whereas the present study takes advantage of a 25 year observation period to provide estimates of the absolute risk of developing COPD. We think that relative risks are often difficult to explain to patients, whereas the absolute risk is easier to comprehend and can help to show the dangers associated with smoking and hopefully strengthen the anti-smoking advice.

\section{Authors' affiliations}

A Løkke, P Lange, P Fabricius, J Vestbo, Department of Cardiology and Respiratory Medicine, Hvidovre Hospital, Hvidovre, Denmark

P Lange, H Scharling, The Copenhagen City Heart Study, Bispebjerg Hospital, Copenhagen, Denmark 
J Vestbo, North West Lung Centre, South Manchester University Hospital Trust, Manchester, UK

This study was funded by the Danish Heart Foundation and Danish Lung Foundation.

Competing interests: none declared.

\section{REFERENCES}

1 Pauwels RA, Rabe KF. Burden and clinical features of chronic obstructive pulmonary disease (COPD). Lancet 2004;364:613-20.

2 Celli BR, MacNee W, Agusti A, et al. Standards for the diagnosis and treatment of patients with COPD: a summary of the ATS/ERS position paper. Eur Respir J. 2004;23: 932-46, Also available at www.thoracic.org and www.ersnet.org.

3 Murray CJ, Lopez AD. Alternative projections of mortality and disability by cause 1990-2020: Global Burden of Disease Study. Lancet 1997;349: 1498-504.

4 Fletcher CM, Tinker, Peto R, et al. The natural history of chronic bronchitis and emphysema. Oxford: Oxford University Press, 1976.

5 Burrows B, Knudson RJ, Camilli AE, et al. The "horse-racing effect" and predicting decline in forced expiratory volume in one second from screening spirometry. Am Rev Respir Dis 1987;135:788-93.

6 Tager IB, Segal MR, Speizer FE, et al. The natural history of forced expiratory volumes. Effect of cigarette smoking and respiratory symptoms. Am Rev Respir Dis 1988;138:837-49.

7 Xu X, Dockery DW, Ware JH, et al. Effects of cigarette smoking on rate of loss of pulmonary function in adults: a longitudinal assessment. Am Rev Respir Dis 1992;146:1345-8.

8 Lange P, Groth S, Nyboe J, et al. Effects of smoking and changes in smoking habits on the decline of $\mathrm{FEV}_{1}$. Eur Respir J 1989;2:811-6.

9 Camilli AE, Burrows B, Knudson RJ, et al. Longitudinal changes in forced expiratory volume in one second in adults. Am Rev Respir Dis 1987; 135:794-9

10 Anthonisen NR, Connett JE, Kiley JP, et al. Effects of smoking intervention and the use of an inhaled anticholinergic bronchodilator on the rate of decline of $\mathrm{FEV}_{1}$. The Lung Health Study. JAMA 1994;272:1497-505.

11 Appleyard M. The Copenhagen City Heart Study. Scand J Soc Med 1989;Suppl 41.
12 Schnohr $P$, Jensen $G$, Lange $P$, et al. The Copenhagen City Heart Study. Tables with data from the third examination 1991-94. Eur Heart $J$ 2001;3(Suppl H).

13 Torén K, Brisman J, Järvholm B. Asthma and asthma-like symptoms in adults assessed by questionnaires. Chest 1993;104:600-8.

14 Lange $P$, Nyboe J, Jensen $G$, et al. Ventilatory function impairment and risk of cardiovascular death and of fatal or non-fatal myocardial infarction. Eur Respir J 1991;4:1080-7.

15 Danish Respiratory Society. Spirometry - a recommendation (in Danish). Copenhagen: Danish Respiratory Society, 1986.

16 Huhti E, Ikkala J. A follow-up study on respiratory symptoms and ventilatory function in a middle-aged rural population. Eur J Respir Dis 1980;61:33-45.

17 Krzyzanowski M, Jedrychowski W, Wysocki M. Factors associated with the change in ventilatory function and the development of chronic obstructive pulmonary disease in a 13-year follow up of the Cracow study. Am Rev Respir Dis 1986;134:1011-9.

18 Vestbo J, Lange P. Can GOLD stage 0 provide information of prognostic value in chronic obstructive pulmonary disease? Am J Respir Crit Care Med 2002;166:329-32.

19 Lindberg A, Jonsson A-C, Rönmark E, et al. Ten-year cumulative incidence of COPD and risk factors for incident disease in a symptomatic cohort. Chest 2005; 127:1544-52.

20 Rennard SI, Vestbo J. The dangerous underestimate of 15\%. Lancet 2006;367:1216-19.

21 Anthonisen NR, Connett JE, Murray RP, for the Lung Health Study Research Group. Smoking and lung function of Lung Health Study participants after 11 years. Am J Respir Crit Care Med 2002;166:675-9.

22 Anthonisen NR, Skeans MA, Wise RA, for the Lung Health Study Research Group, et al. The effects of a smoking cessation intervention on 14.5 year mortality. Ann Intern Med 2005; 142:233-9.

23 Bergdahi IA, Torén K, Eriksson K, et al. Increased mortality in COPD among construction workers exposed to inorganic dust. Eur Respir J 2004;23:402-6.

24 Ezzati M, Lopez AD. Estimates of global mortality attributable to smoking in 2000. Lancet 2003;362:847-52.

25 Lange P. Development and prognosis of chronic obstructive pulmonary disease with special reference to the role of tobacco smoking. Danish Med Bull 1992;39:30-48.

26 Mannino DM, Buist AS, Petty TL, et al. Lung function and mortality in the United States: data from the First National Health and Nutrition Examination Survey follow up study. Thorax 2003;58:388-93.

27 Mannino DM, Homa DM, Akinbami U, et al. Chronic obstructive pulmonary disease surveillance - United States, 1971-2000. MMWR 2002;51:1-16. 